\title{
PREPRINT
}

Author-formatted, not peer-reviewed document posted on 18/10/2021

DOI: https://doi.org/10.3897/arphapreprints.e76705

\section{Scanning the horizon for invasive plant threats to Florida, USA}

Amy Kendig, Susan Canavan, Patti Anderson, Stephen Flory, Lyn Gettys, Doria Gordon, Basil lannone III, John Kunzer, Tabitha Petri, (D) Ian Pfingsten, Deah Lieurance 


\section{Scanning the horizon for invasive plant threats to Florida, USA}

Amy E. Kendig ${ }^{1, *}\left(\right.$ ORCiD: 0000-0002-2774-1795), Susan Canavan ${ }^{1,2^{*}}$ (ORCiD: 0000-00027972-7928), Patti J. Anderson ${ }^{3}$ (0000-0002-0870-7858), S. Luke Flory ${ }^{1}$ (ORCiD: 0000-00033336-8613), Lyn A. Gettys ${ }^{4}$ (ORCiD: 0000-0001-7785-2867), Doria R. Gordon ${ }^{5,6}$ (ORCiD: 0000-0001-6398-2345), Basil V. Iannone III $^{7}$ (ORCiD: 0000-0002-2477-7573), John M. Kunzer $^{8}$, Tabitha Petri ${ }^{9}$ (ORCiD: 0000-0002-0231-1983), Ian A. Pfingsten ${ }^{10}$ (ORCiD: 00000002-9456-9905), Deah Lieurance ${ }^{1}$ (ORCiD: 0000-0001-8176-3146)

1. Agronomy Department, University of Florida, Gainesville, FL, 32611, USA

2. Department of Invasion Ecology, Institute of Botany, Czech Academy of Sciences, Průhonice, Czech Republic

3. Botany Section, Division of Plant Industry, Florida Department of Agriculture and Consumer Services, Gainesville, FL, 32608, USA

4. Fort Lauderdale Research and Education Center, University of Florida, Davie, FL, 33314, USA

5. Environmental Defense Fund, Washington, D.C., 20009, USA

6. Department of Biology, University of Florida, Gainesville, FL, 32611, USA

7. School of Forest, Fisheries, and Geomatic Sciences, University of Florida, Gainesville, FL,32622, USA

8. Florida Fish and Wildlife Conservation Commission, Invasive Plant Management Section, Tallahassee, FL, 32399, USA

9. School of Natural Resources and Environment, University of Florida, Gainesville, FL, 32611, USA

10. Wetland and Aquatic Research Center, U.S. Geological Survey, Gainesville, FL, 32653, USA

*AEK and SC contributed equally to this work

Corresponding author: AEK (aekendig@ gmail.com)

Running head: Florida invasive plant horizon scan 


\section{Abstract}

33 Early detection and eradication of invasive plants are more cost-effective than managing well-established invasive plant populations and their impacts. However, there is high uncertainty around which taxa are likely to become invasive in a given area. Horizon scanning, which pairs rapid risk assessment with consensus building among experts, can help identify invasion threats. We performed a horizon scan of potential invasive plant threats to Florida, USA - a state with a high influx of introduced species, conditions that are favorable for plant establishment, and a history of negative impacts from invasive plants. We began with a list of 2128 non-native plant species and subspecies that are crop pests or invasive somewhere in the world and used publicly available data to prioritize 100 taxa for rapid risk assessment. We derived overall invasion risk scores by evaluating the likelihood and certainty of each of the 100 taxa arriving, establishing, and having an impact in Florida. Through the rapid risk assessments and a consensus-building discussion, we identified six plant taxa with high overall risk scores ranging from 75 to 100 out of a possible 125 . The six taxa are globally distributed, easily transported to new areas, found in regions with climates similar to Florida's, and can impact native plant communities, human health, or agriculture. We recommend more thorough risk assessments for each of these six species and, if appropriate, policy and management actions to limit invasive plant introduction and

50 establishment in Florida.

\section{Keywords}

53 Avena fatua, certainty, Cytisus scoparius, horizon scan, Ligustrum vulgare, Phalaris

54 arundinacea, rapid risk assessment, prevention 


\section{Introduction}

Potential impacts of invasive species, and invasive plants in particular, are daunting given the high numbers of species introduced to novel areas each year, with rates predicted to increase in the future (Seebens et al. 2020). Governments and private landowners take responsibility for controlling invasive plant populations and mitigating their negative impacts after they arrive (Lovell and Stone 2005, Pimentel 2009) after their arrival. Preventing the introduction and initial spread of invasive plants, however, is generally less expensive than managing established populations and avoids potential ecological and economic losses (Simberloff 2003, Keller et al. 2007, Sheley et al. 2015). Unfortunately, the benefits of prevention are difficult to quantify and involve high uncertainty, making post-invasion control the more common approach (Simberloff 1997a, Finnoff et al. 2007, Early et al. 2016). Thus, programs that help identify which non-native plant taxa have a high probability of becoming problematic invaders in a given area are essential for providing the first lines of defense against plant invasions, such as informing trade policies and identifying control priorities if highly ranked taxa are discovered in a new habitat.

Horizon scanning is the systematic examination of information to identify potential threats, risks, emerging issues, and opportunities that can inform policy (Sutherland and Woodroof 2009, Amanatidou et al. 2012, Könnölä et al. 2012). This technique has been applied to a variety of topics including policy analysis (Könnölä et al. 2012), medical technology (van der Maaden et al. 2018), and various conservation issues (Gusset et al. 2014, Brown et al. 2016, Cooke et al. 2020, Sutherland et al. 2021). In Europe, horizon scanning of emerging invaders and their pathways for introduction has informed policy and guided resource allocation to research and prevention efforts (Parrott et al. 2009, Matthews et al. 2014, Roy et al. 2014, Gallardo et al. 2016, Lucy et al. 2020). However, horizon scanning has yet to be used to identify invasive species threats in the U.S. (but see Ricciardi et al. 2017), where non-native plant and animal introduction numbers are among the highest in the world (Seebens et al. 2017).

Florida is one of the most important states for regulating invasive plants in the U.S. because nearly $85 \%$ of all non-native plants imported to the contiguous U.S. enter through one of 35 shipping ports and airports in Florida (Gordon and Thomas 1997, Enterprise Florida 2021). As international trade continues to grow, so does the frequency of intentional and accidental introductions (Early et al. 2016). In addition to being an entry point for invasive species to the rest of the country, Florida is particularly vulnerable to the establishment of invasive plants due to its tropical/subtropical climate and diverse ecosystems (Simberloff 1997b, Pyšek et al. 2017). Management of invasive plants in Florida's conservation areas costs nearly $\$ 45$ million per year (Hiatt et al. 2019) and invasive species (including plants, insects, and pathogens) cost Florida's agriculture industry at least $\$ 179$ million per year (Coffman et al. 2001). Accordingly, Florida residents are highly supportive of preventing biological invasions (Huang and Lamm 2016). Identifying potential invaders before or soon after they enter Florida can reduce ecological and economic losses to the state as well as prevent the spread of invasive plants nationally - a goal of the U.S. Plant Protection Act (U.S. Congress 2000).

Our aim was to use horizon scanning to create a ranked list of non-native plants that are likely to arrive and establish in Florida and have an impact on native biodiversity, the economy, or human health within the next ten years (2020-2030). A successful horizon scan for potential invaders relies on the integration of risk assessment and consensus building (Roy et al. 2015). We began with a list of potential invasive species and subspecies generated 
by the Centre for Agriculture and Biosciences International (CABI), and used publicly available data to identify the 100 plant taxa most likely to arrive and have impacts in Florida. Then, during the risk assessment phase, experts assigned scores for likelihood of arrival, establishment, and impacts in Florida to the 100 taxa. Risk assessments were peer-reviewed, and taxa were ranked based on their scores. Finally, in the consensus building phase, experts reviewed the ranked list and suggested modifications. Here, we present the ranked list of potential invasive plant threats to Florida, which can be used to inform research, management, and policy aimed at reducing invasive plant impacts in Florida.

\section{Methods}

We adapted the horizon scanning method outlined by Sutherland et al. (2011) and Roy et al. $(2014,2015)$ to develop a ranked list of invasive plant threats and their potential pathways for arrival to the state of Florida over the next ten years (2020-2030). We chose a ten year time frame to capture threats in the near future and to establish a minimum frequency (once every ten years) for updating the horizon scan with new information.

\section{Expert panel and workshop}

We (the authors) formed the expert panel, providing knowledge of Florida's natural systems and existing invasive plants, including experience in invasion ecology, botany, policy, and data analysis. We are employed by governmental, academic, and non-profit organizations (Environmental Defense Fund, Florida Department of Agriculture and Consumer Services, Florida Fish and Wildlife Commission, University of Florida, and United States Geological Survey), which supported our participation. We organized and attended a workshop in December 2019, during which we designed criteria for selecting taxa to assess (see Assembling a list), discussed the rapid risk assessment tool (see Assessing and scoring the taxa), and identified online resources for completing the rapid risk assessments.

\section{Assembling a list}

Using the horizon scan tool developed by CABI (an inter-governmental not-for-profit organization that provides information and expertise on agriculture and the environment), we generated a preliminary list of invasive taxa and crop pests that are not known to be present in Florida based on CABI's databases (CABI 2018). The tool consolidates information from the CABI Invasive Species Compendium and Crop Protection Compendium, which are science-based encyclopedic databases. The tool generated a list of 9629 taxa, 2128 of which were in the kingdom Plantae.

We first corrected the preliminary list for synonyms by compiling accepted names and synonyms from the Atlas of Florida Plants (Wunderlin et al. 2019), the Taxonomic Name Resolution Service (TNRS; Boyle et al. 2015), and the Integrated Taxonomic Information System (ITIS; ITIS n.d.; see Suppl. material 1: Methods S1 for more details), which increased our list to 2360 taxa. The modified CABI list was then trimmed based on several criteria (Fig. 1), including: climatically matched to Florida, not naturalized in Florida (i.e., a selfsustaining population), not on a Florida or federal noxious weed list, naturalized outside of its native range, historically weedy, and commonness (Suppl. material 2: Table S1). If taxa met a criterion, they were retained for further assessment in the next stage. We assessed commonness by the number of global occurrences (GBIF.org 2021a) and selected the top 100 $(12 \%)$ for further assessment, which was the largest number of taxa that the experts felt they could feasibly evaluate. 


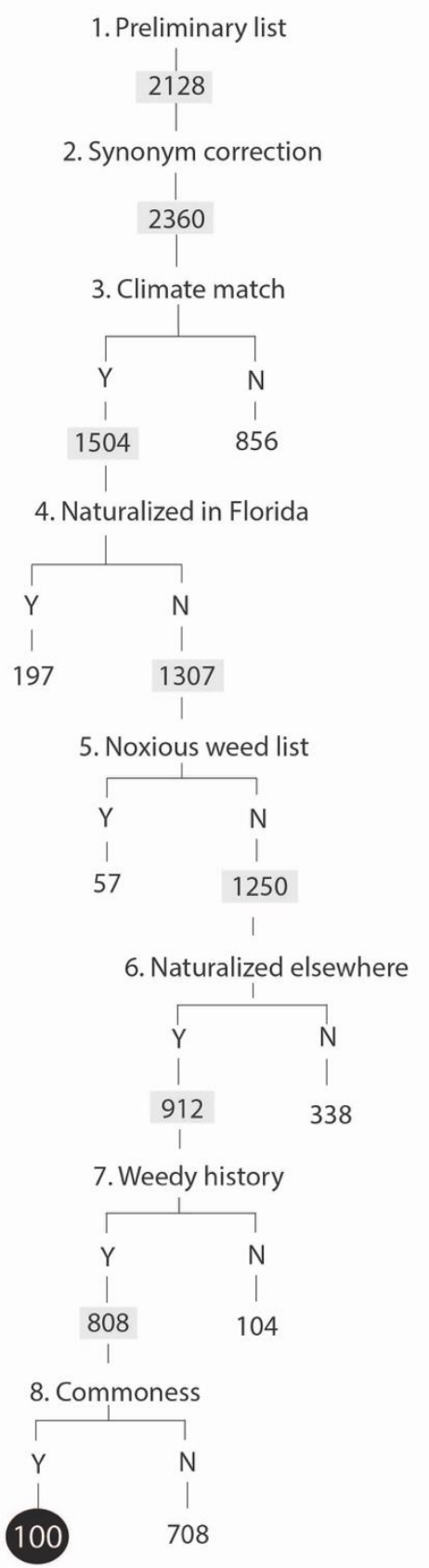

155 Figure 1. Criteria for selecting taxa for rapid risk assessment. The criteria included the

156 following systematic steps: (1) a preliminary list of 2128 taxa; (2) correcting for synonyms,

157 which increased the original list to 2360; (3) climate matching with Köppen-Geiger climate

158 zones (Kottek et al. 2006, CABI 2018), which identified 1504 taxa that could potentially become established in Florida if climate were the only limiting variable; (4) 197 taxa were already naturalized in Florida (Wunderlin et al. 2019) and removed from the list; (5) 57 taxa were already listed on state or federal noxious weed lists (State of Florida 2008, 2020, USDA 2017, FISC 2019) and were removed from the list; (6) taxa that were naturalized somewhere outside of their native range (van Kleunen et al. 2019), suggesting the ability to establish in

164 habitats where they did not co-evolve with other species, were selected (912 taxa); (7) taxa

165 with a record of "weediness", suggesting the ability to produce a self-sustaining population and have at least mild impacts on the surrounding environment (Randall 2017), were selected 
167 (808 taxa); (8) the top 100 taxa, ranked by number of global occurrences (GBIF.org 2021a), were selected. More details on the datasets used to inform these criteria can be found in Suppl. material 1: Methods S1.

We used expert opinion to remove and add taxa from the list before and after finalizing the top 100. Pastinaca sativa was previously assessed by one of the experts and determined to be not a threat to Florida (removed before commonness was assessed). Two taxa were removed from the list of 100 taxa: Rosmarinus officinalis and Galeopsis tetrahit. Rosmarinus officinalis was known by experts to be naturalized in Florida and found to have 13 recent herbarium records. There was not enough information on Galeopsis tetrahit available to complete the rapid risk assessment and very few of its GBIF occurrences were inside Florida's Köppen-Geiger climatic zones (Galeopsis tetrahit L. in GBIF Secretariat 2021). Because GloNAF, the database used for criterion 6 (Fig. 1), only included vascular plants (van Kleunen et al. 2019), an undesirable side effect of the filtering process was that nonvascular plants were removed without taking other criteria into account. To more rigorously evaluate non-vascular plants, we added the non-parasitic terrestrial and freshwater taxa from the initial CABI list that were in the phyla Chlorophyta, Heterokontophyta, Phaeophyta, Rhodophyta, or Streptophyta (the phyla Bryophyta, Marchantiophyta, and Anthocerophyta were not in the original list) to the list: Aegagropila linnaei and Campylopus introflexus. We therefore ended with 100 taxa (two removed and two added).

\section{Assessing and scoring the taxa}

Nine of us evaluated taxa using a rapid risk assessment tool modified from Roy et al. (2014). First, we used a species not included in the final list to assess the tool for clarity of instructions, the time it took to complete the assessment, and inconsistencies across assessments. Then, we completed rapid risk assessments with a standardized set of resources: the tool, instructions, a list of taxa to assess and their synonyms, the list of websites compiled during the workshop, information about Florida's plant hardiness zones (USDA 2012) and Köppen-Geiger climate zones (Kottek et al. 2006), and a list of search terms for search engines. Because the risk assessment tool is designed to be completed rapidly, we aimed to spend less than two hours assessing each taxon. Eight of us completed ten assessments each and one of us completed twenty.

We scored the likelihood of arrival, establishment, and negative impacts (environmental, socioeconomic, and human health) on a scale of 1 (very low) to 5 (very high). To estimate the likelihood of arrival, experts considered the current distribution of the taxon, the availability of the taxon for purchase, history of invasion by the taxon in other regions, and the presence of a plausible arrival pathway (Table 1). To estimate the likelihood of establishment (i.e., developing a self-sustaining population), experts considered the occurrences and distribution of the taxon within regions with Köppen-Geiger climate zones matching Florida (Table 1). Experts also considered ecological properties of both the taxon and Florida habitats, including time to reproductive maturity, reproduction rate, dispersal mechanism, propagule pressure, tolerance of a broad range of environmental conditions, amount of nurturing required, resource availability, and natural enemies. To estimate the likelihood of negative impacts, experts used a scoring rubric modified from the Invasive Species Environmental Impact assessment protocol (Branquart 2009), the Environmental Impact Classification of Alien Taxa (EICAT; Blackburn et al. 2014, Hawkins et al. 2015), and the Socio-Economic Impact Classification of Alien Taxa (SEICAT; Bacher et al. 2018; Table 1). The overall risk score was the product of arrival, establishment, and impact likelihood scores. We provided brief justifications for our scores and assigned certainty scores that ranged from very low 
217 (i.e., all scores were equally likely) to high (i.e., could confidently eliminate all other scores).

218 The overall certainty score was the score most consistent with three component certainty

219 scores.

Table 1. Rubrics for scoring likelihood of arrival, establishment, and impacts of potential invasive plants in Florida.

\begin{tabular}{|c|c|c|}
\hline Category & Criteria & Score \\
\hline \multirow[t]{5}{*}{ Arrival $^{\dagger}$} & $\begin{array}{l}\text { Closest observation to Florida }{ }^{\ddagger} \text { and closest online seller to Florida }{ }^{\S} \text { are outside of the } \\
\text { contiguous U.S. }\end{array}$ & 1 \\
\hline & $\begin{array}{l}\text { Closest observation to Florida is within the contiguous U.S., but not in the southeastern I } \\
\text { U.S., and the closest online seller to Florida is outside of the contiguous U.S. }\end{array}$ & 2 \\
\hline & $\begin{array}{l}\text { Closest observation to Florida and closest online seller to Florida are within the } \\
\text { contiguous U.S., but not in the southeastern U.S. or closest observation to Florida is in } \\
\text { the southeastern U.S., but not in Florida, and the closest online seller to Florida is } \\
\text { outside the contiguous U.S. }\end{array}$ & 3 \\
\hline & $\begin{array}{l}\text { Closest observation to Florida is within the southeastern U.S., but not in Florida, and } \\
\text { the closest online seller is within the contiguous U.S. or the southeastern U.S., but not } \\
\text { in Florida. }\end{array}$ & 4 \\
\hline & The taxon has been observed or sold within Florida. & 5 \\
\hline \multirow{5}{*}{$\begin{array}{l}\text { Establish } \\
\text { ment }^{\dagger}\end{array}$} & No observations in areas with matching Köppen-Geiger (KG) zones to Florida ${ }^{\mathbb{I I}}$ & 1 \\
\hline & Few observations in one area with matching KG zones to Florida. & 2 \\
\hline & $\begin{array}{l}\text { Many observations in one area or few observations in multiple areas with matching KG } \\
\text { zones to Florida. }\end{array}$ & 3 \\
\hline & Many observations in multiple areas with matching KG zones to Florida. & 4 \\
\hline & $\begin{array}{l}\text { Criteria for score } 4 \text { plus evidence of a biological strategy that aids establishment or } \\
\text { evidence of establishment in Florida. }\end{array}$ & 5 \\
\hline \multirow[t]{5}{*}{ Impact } & $\begin{array}{l}\text { Unlikely to cause negative impacts on the native biota or abiotic environment, human } \\
\text { well-being, or economic systems. }\end{array}$ & 1 \\
\hline & $\begin{array}{l}\text { Likely to cause (a) declines in the performance (e.g., biomass, body size) of native } \\
\text { biota, but no decline in native population sizes or (b) income loss, minor health } \\
\text { problems, higher effort or expense to participate in activities, increased difficulty in } \\
\text { accessing goods, or minor disruption of social activities, but no significant impact on } \\
\text { participation in normal activities. The taxon has no other impacts that would cause it to } \\
\text { be classified in a higher impact category. }\end{array}$ & 2 \\
\hline & $\begin{array}{l}\text { Likely to cause (a) declines in the population size(s) of native species, but no changes } \\
\text { to the structure of communities or to the abiotic or biotic composition of ecosystems or } \\
\text { (b) changes in the size of social activities, with fewer people participating, but the } \\
\text { activity is still carried out. These changes to social activities could be linked to } \\
\text { accessibility to the activity area or mild effects to human health (e.g., allergies). The } \\
\text { taxon has no impacts that would cause it to be classified in a higher impact category. }\end{array}$ & 3 \\
\hline & $\begin{array}{l}\text { Likely to cause (a) the local or population extinction of at least one native species, } \\
\text { leading to reversible changes in the structure of communities, the abiotic or biotic } \\
\text { composition of ecosystems or (b) the local disappearance of a social or economic } \\
\text { activity from all or part of the area invaded by the alien taxon, collapse of the specific } \\
\text { activity, switch to other activities, abandonment of activity without replacement, } \\
\text { emigration from region, or moderate effects to human health. The taxon has no impacts } \\
\text { that would cause it to be classified in a higher impact category. }\end{array}$ & 4 \\
\hline & $\begin{array}{l}\text { Likely to cause (a) the replacement and local extinction of native species and will } \\
\text { produce irreversible changes in the structure of communities and the abiotic or biotic }\end{array}$ & 5 \\
\hline
\end{tabular}


composition of ecosystems or (b) local disappearance of a social or economic activity from all or part of the area invaded by the alien taxon or major effects to human health.

†Arrival and Establishment rubrics were applied during the review phase rather than the assessment phase. Scores were adjusted by up to one point based on additional information in the assessments.

Observations based on GBIF.org (2020) or information provided by the assessor or reviewer. §Sellers located with PlantScout (2020), Betrock’s Plant Search (Rosenthal 2020), and google.com.

For our purposes (proximity to Florida), southeastern states include Georgia, Alabama, South Carolina, North Carolina, Tennessee, and Mississippi.

"Observations based on GBIF.org (2020) or information provided by the assessor or reviewer. Florida's Köppen-Geiger zones include Af, Am, Aw, and Cfa (Kottek et al. 2006).

We identified one or more potential pathways for the taxa to arrive in Florida based on an established framework (Hulme et al. 2008, CBD 2014, Harrower et al. 2018). Briefly, the pathways included "release in nature" (intentional release, such as for erosion control), "escape from confinement" (intentional commodity that escapes, such as a horticultural taxon), "transport contaminant" (associated with the transport of a specific commodity, such as a seed contaminant), "transport stowaway" (other forms of unintentional transport, such as through soil on equipment), "corridor" (through human infrastructure linking previously unconnected areas, such as a waterway), and unaided (natural dispersal).

\section{Reviewing and modifying scores}

In the first round of reviews, ten of us reviewed ten assessments each. We searched for each taxon in references that we found helpful when completing risk assessments and filled in information where the assessor indicated that the certainty was "low" or "very low". We changed scores, edited justifications, and wrote comments, differentiating our text from the original assessor by using red font (Suppl. material 3: Table S2). We aimed to complete the reviews efficiently, spending 30 minutes or fewer on each. We then ranked the taxa by their overall risk score and all group members read the reviewed risk assessments.

\section{Consensus building}

During the two hour virtual meeting, we discussed taxa in descending order of scores. We spent extra time discussing taxa with more controversial scores, such as taxa with large discrepancies between scores assigned by the assessor and reviewer, which were reviewed again following consensus building. In addition, Solidago canadensis was removed from the list, creating a final list of 99 taxa. Taxonomic subunits of $S$. canadensis are difficult to distinguish (CABI 2021), creating ambiguity about whether $S$. canadensis is already established in Florida (Wunderlin et al. 2019, GBIF.org 2021b). We therefore could not evaluate the risk of $S$. canadensis arriving in Florida.

We determined overall risk score thresholds to categorize taxa as high, medium, or low risk: a taxon scoring $\geq 64$ (i.e., an average score of 4 for each variable of arrival, establishment, and impact) was categorized as high risk, a taxon with a score between 27 (i.e., an average score of 3 for each variable) and 63 as medium risk, and a taxon with a score less than 27 as low risk.

\section{Analysis of risk scores}

We evaluated whether peer-review and consensus building significantly affected overall risk scores with a paired two-sample $t$-test, comparing scores from the first assessments to those 
of the final list. We also evaluated how variation among experts and characteristics of the taxa affected the overall risk scores. We fit a generalized linear regression with a negative binomial error structure to the overall risk scores with the expert who completed the assessment $(N=9)$, expert certainty about the overall score (very low, low, medium, or high), whether the typical habitat of the plant taxon is terrestrial or aquatic, the number of records of the taxon in the U.S., and the year of the earliest record of the taxon in the U.S. as independent variables. To determine the number of records and the earliest record of each taxon in the U.S., we used the package 'rgbif' (Chamberlain et al. 2021) to extract all GBIF records in the U.S. for each taxon, selecting records that had coordinates and no geospatial issues (GBIF.org 2021b). One taxon had no records in the U.S., so we used the current year for its earliest record value. Number of records and earliest record were centered and scaled and were not significantly correlated with each other $(r=0.04, P=0.68)$. We fit the model using the 'MASS' package (Venables and Ripley 2002), evaluated the fit using the 'DHARMa' package (Hartig and Lohse 2020), tested the significance of each independent variable using likelihood ratio tests, and compared factor levels using the 'emmeans' package (Lenth et al. 2021). All analyses were conducted in R version 4.0.2 (R Core Team 2020).

\section{Taxa characteristics}

We evaluated whether plant taxonomic families were under- or overrepresented in the CABI plant list and in the final list using a resampling procedure (Daehler 1998). We first extracted all accepted species names and their family names from The Plant List using the taxize package (Chamberlain and Szoecs 2013, TPL 2013), resulting in a dataset of 373,847 taxa. The CABI list contained 158 families (with 2091 taxa) in The Plant List (vascular plants and bryophytes). We re-sampled 2091 taxa without replacement from The Plant List dataset 10,000 times. Taxa were replaced between iterations and we counted the number of taxa per family each iteration. We set the threshold for statistical significance to $P<0.0003(0.05$ divided by the number of families, consistent with a Bonferroni correction; Daehler 1998). Therefore, families with fewer than three iterations during which the sampled number of taxa was greater (less) than or equal to the number of taxa in the CABI list from that family were considered overrepresented (underrepresented). We repeated this procedure with different values for the final list: 34 families with 98 taxa, 1,000 iterations, $P<0.0015$, and families with one or fewer iterations.

To evaluate the native and introduced ranges of taxa in the final list, we researched the their distributions using the Plants of the World database (for 95 of the 99 taxa; POWO 2021), the CABI Invasive Species Compendium (CABI 2021), the Global Compendium of Weeds (Randall 2017), and GBIF (GBIF.org 2020). One species, Aegagropila linnaei, was removed from the analysis because its native range is unclear. We summarized distributions using the World Bank Development Indicator regions in the 'countrycode' package (Arel-Bundock et al. 2018).

311

312

313

314

\section{Results}

\section{High risk taxa}

Six plant taxa received risk scores greater than or equal to 64 (Fig. 2), indicating that these taxa are likely to invade Florida in the next 10 years. We had high certainty about the risk scores for four taxa: Ligustrum vulgare, Cytisus scoparius, Phalaris arundinacea, and Avena fatua. We had medium certainty for the other two taxa: Agrostis capillaris and Persicaria hydropiper. Three of the taxa were considered very likely to arrive in Florida (arrival score $=$ 5 out of 5): L. vulgare, A. fatua, and P. hydropiper. This conclusion was based on: herbarium 
321

322

323

324

325

326

327

328

329

330

331

332

333

334

335

336

337

without naturalization within the last 20 years (fewer than three records in wild areas); and records of seeds sold within the U.S. at the time of the assessment (Suppl. material 3: Table S2). All six taxa were considered very likely to establish in Florida (establishment score $=5$ out of 5) because they occur in other regions of the world with climates similar to Florida and in some cases, the taxon is known to have high reproductive capacity (Suppl. material 3: Table S2). While none of the taxa were considered very likely to cause economic or environmental impacts in Florida, four taxa received the next highest impact score (impact score $=4$ out of $5 ; L$. vulgare, $C$. scoparius, $P$. arundinacea, and A. capillaris). These four taxa have impacted native vegetation through competition, produce pollen that can be a human allergen, and some are agricultural weeds (Suppl. material 3: Table S2). Information about the six species from a handful of sources can help inform potential future policy actions (Table 2): the taxa are native to a number of regions in the eastern hemisphere and have global distributions; they have cultural and economic uses that have facilitated their introduction to new regions in the past; they can disperse through unintentional pathways; they are managed through various, often integrated, approaches; and they are included in U.S. state noxious weed lists or laws.
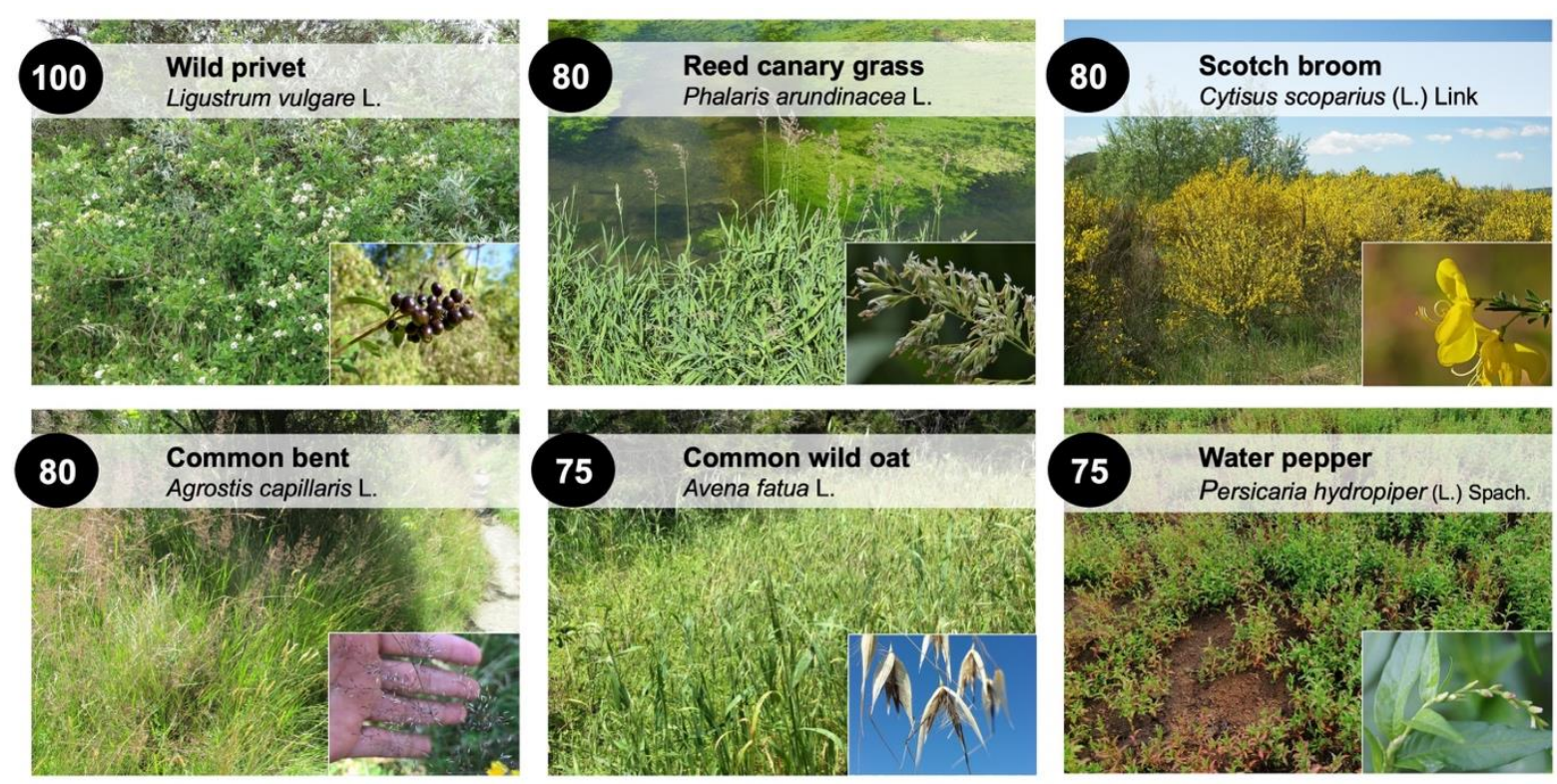

338

339

340

341

342

343

344

345

Figure 2. The six taxa that were designated as high risk for invasion potential in Florida. Overall risk scores are in white circles (maximum possible score is 125). (Photos: Meneerke bloem, Isidre blanc, Andreas Eichler, Stefan.lefnaer, CC BY-SA 4.0; Robert Flogaus-Faust, CC BY 4.0; Rasbak, CC BY-SA 3.0; Willow, CC-BY 2.5; Mary Joyce, Katrice Baur, scottq1, rae117, CC BY-NC 4.0; Christian Grenier, CC0 1.0).

Table 2. Characteristics of the six high risk species.

\begin{tabular}{|l|c|c|c|c|c|}
\hline Species & Native range $^{\dagger}$ & $\begin{array}{c}\text { Introduced } \\
\text { countries }^{\ddagger}\end{array}$ & $\begin{array}{c}\text { Arrival pathways and } \\
\text { uses }^{\S}\end{array}$ & $\begin{array}{c}\text { Management } \\
\text { approaches }^{\text {L }}\end{array}$ & $\begin{array}{c}\text { States } \\
\text { listed }\end{array}$ \\
\hline $\begin{array}{l}\text { Ligustrum } \\
\text { vulgare }\end{array}$ & $\begin{array}{c}\text { Europe, western } \\
\text { Asia, northern } \\
\text { Africa }\end{array}$ & $\begin{array}{c}\text { Argentina, Australia, } \\
\text { Brazil, Canada, New } \\
\text { Zealand, South } \\
\text { Africa, United States, }\end{array}$ & $\begin{array}{c}\text { agroforestry, escape from } \\
\text { confinement/garden, graft } \\
\text { stock, landscape } \\
\text { improvement, medicinal, } \\
\text { ornamental, shade }\end{array}$ & $\begin{array}{c}\text { mechanical } \\
\text { (pulling, digging, } \\
\text { cuttting), chemical } \\
\text { (cut and spray, stem } \\
\text { injections) }\end{array}$ & 11 \\
\hline $\begin{array}{l}\text { Phalaris } \\
\text { arundinacea }\end{array}$ & Asia, Europe, \\
Central America, & $\begin{array}{c}\text { Ethiopia, Kenya, } \\
\text { Tanzania, Uganda }\end{array}$ & $\begin{array}{c}\text { erosion control, fodder } \\
\text { crop, fiber, ornamental }\end{array}$ & $\begin{array}{c}\text { burning, discing, } \\
\text { mowing, herbicides }\end{array}$ & 10 \\
\hline
\end{tabular}




\begin{tabular}{|c|c|c|c|c|c|}
\hline & $\begin{array}{l}\text { North America\#, } \\
\text { southern/eastern/ } \\
\text { northern Africa }\end{array}$ & & & & \\
\hline $\begin{array}{l}\text { Cytisus } \\
\text { scoparius }\end{array}$ & Europe & $\begin{array}{c}\text { Argentina, Australia, } \\
\text { Bolivia, Brazil, } \\
\text { Canada, Chile, } \\
\text { China, India, Iran, } \\
\text { Japan, New Zealand, } \\
\text { South Africa, United } \\
\text { States }\end{array}$ & $\begin{array}{c}\text { animal-assisted, ballast } \\
\text { water, botanical gardens } \\
\text { and zoos, disturbance, } \\
\text { escape from } \\
\text { confinement/garden, fiber, } \\
\text { garden waste disposal, } \\
\text { hedge/windbreak, } \\
\text { medicinal, transport } \\
\text { stowaway, ornamental, } \\
\text { waterways }\end{array}$ & $\begin{array}{l}\text { burning (with other } \\
\text { approaches), } \\
\text { grazing, mulching, } \\
\text { pulling (outlying } \\
\text { plants), chemical } \\
\text { (cut and spray, } \\
\text { foliar spray, stem } \\
\text { injections), } \\
\text { biological control }\end{array}$ & 14 \\
\hline $\begin{array}{l}\text { Agrostis } \\
\text { capillaris }\end{array}$ & $\begin{array}{c}\text { central/western/ } \\
\text { southwestern Asia, } \\
\text { Europe, North } \\
\text { Africa, }\end{array}$ & $\begin{array}{l}\text { Argentina, Australia, } \\
\text { Bhutan, Brazil, } \\
\text { Canada, Chile, } \\
\text { Greenland, India, } \\
\text { New Zealand, Saint } \\
\text { Helena, Saint Pierre } \\
\text { and Miquelon, South } \\
\text { Georgia and the } \\
\text { South Sandwich } \\
\text { Islands, United States }\end{array}$ & $\begin{array}{c}\text { animal-assisted, } \\
\text { disturbance, erosion } \\
\text { control, fodder, grass } \\
\text { contaminant, horticulture, } \\
\text { pasture, landscape } \\
\text { rehabilitation, turf grass } \\
\text { (lawns and golf), wind and } \\
\text { water }\end{array}$ & $\begin{array}{c}\text { crop rotations, } \\
\text { mechanical } \\
\text { (pulling, ploughing, } \\
\text { grubbing and } \\
\text { harrowing), } \\
\text { herbicides }\end{array}$ & 5 \\
\hline Avena fatua & Central Asia & $\begin{array}{c}\text { Canada, United } \\
\text { States (present in } 74 \\
\text { other countries, but } \\
\text { "introduced" status } \\
\text { not provided) }\end{array}$ & $\begin{array}{l}\text { fodder, forage, gene source } \\
\text { for disease and drought } \\
\text { resistance, medicinal, seed } \\
\text { contaminant, transport } \\
\text { stowaway }\end{array}$ & $\begin{array}{l}\text { burning, crop } \\
\text { rotation, herbicides, } \\
\text { soil cultivation, soil } \\
\text { solarization }\end{array}$ & 4 \\
\hline $\begin{array}{l}\text { Persicaria } \\
\text { hydropiper }\end{array}$ & Europe & $\begin{array}{l}\text { "Introduced" status } \\
\text { not provided, but } \\
\text { present in } 48 \\
\text { countries }\end{array}$ & culinary, medicinal & herbicides, pulled & 1 \\
\hline
\end{tabular}

${ }^{\dagger}$ Geographic regions where the taxon is native (CABI 2021, Native Plant Trust 2021)

Countries where the taxon has been introduced (CABI 2021)

${ }^{\S}$ Known pathways for arrival and human uses (CABI 2021)

IApproaches used to control the taxon (CABI 2021)

350 IU.S. states in which the taxon is included in a prohibited list or law (EDDMapS 2021)

$351 \quad$ \#See Taxa characteristics section for more details

\section{Medium risk taxa}

Twenty-three taxa received medium risk scores (greater than or equal to 27, but less than 64; Fig. 3). Two taxa, Matricaria chamomilla and Symphytum officinale, were considered very likely to arrive in Florida (score $=5$ ) because there were occurrence records in Florida, including two for $S$. officinale that suggested escape (it is planted as an ornamental, Table S2). Symphytum officinale was considered likely to establish in Florida (establishment score $=4$ ), but unlikely to have impacts (impact score $=2$ ). Four taxa were considered very likely to establish in Florida (establishment score = 5) - Hypericum perforatum, Malva sylvestris, Matricaria chamomilla, and Mentha aquatica - because they occur in areas with climate similar to Florida and M. chamomilla readily self-seeds (Table S2). Hypericum perforatum, M. sylvestris, and M. aquatica were considered likely to arrive in Florida (arrival score $=4$ ) and potentially likely to have negative impacts (impact score $=3$ ), but $M$. chamomilla was considered likely to have only minimal negative impacts (impact score $=2$ ). These four taxa are sold as ornamental plants within the U.S., have been reported in the southeastern U.S. in the past 20 years, and can naturally disperse (Table S2). None of the plant taxa in the medium 
368 risk group were considered very likely to have negative impacts. We had high certainty about 369 the scores of two taxa, medium certainty about the scores for 18 taxa, and low certainty about 370 the scores for three taxa. The three taxa for which we had low certainty about their scores 371 received relatively low risk scores: Symphytum officinale (overall risk score $=40$ ), Jacobaea 372 vulgaris (overall risk score $=27$ ), and Calystegia sepium spp. sepium (overall risk score $=$ 373 27). 
A

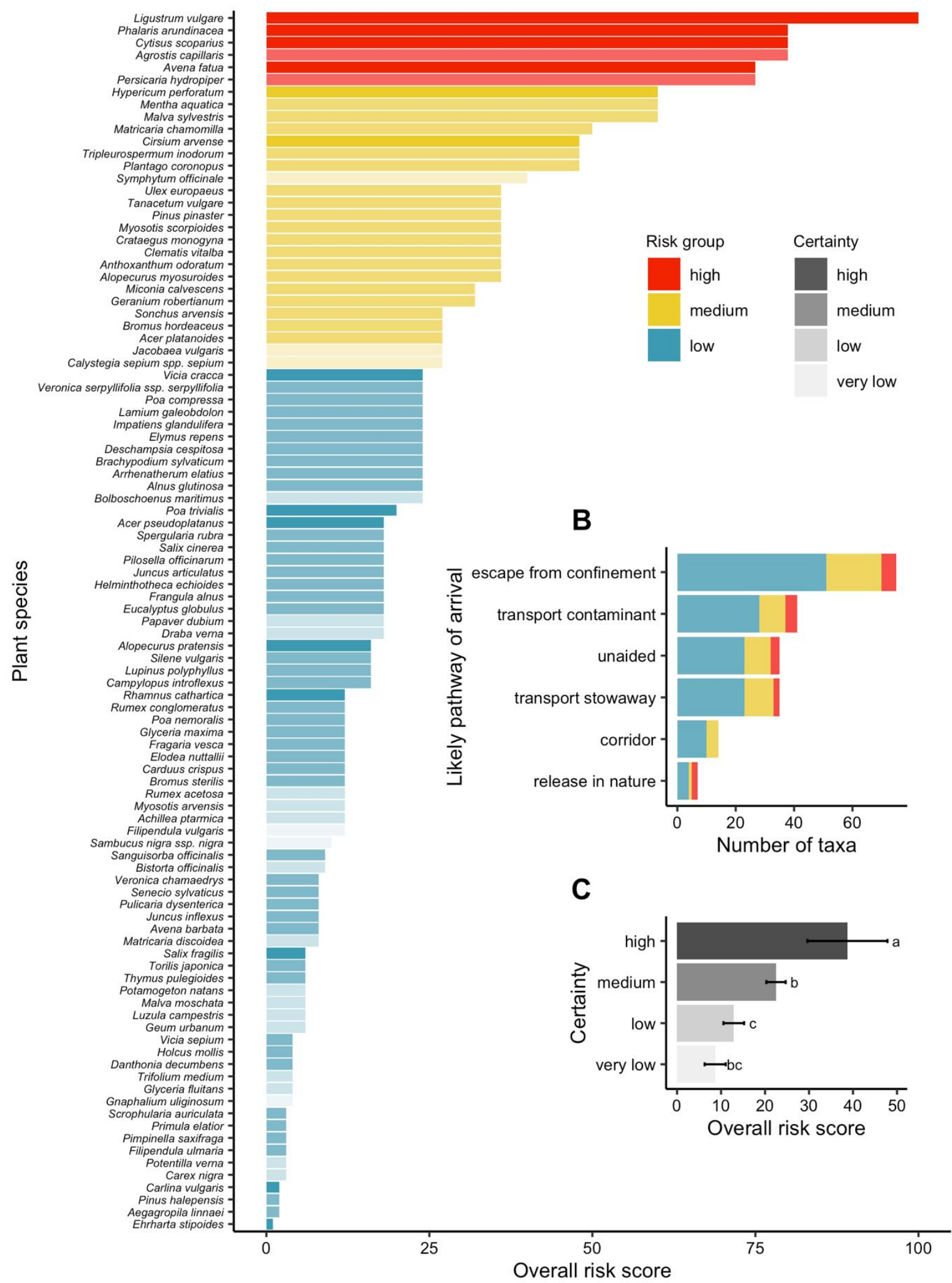

376 Figure 3. Horizon scan scores. A The overall risk scores for 99 taxa, divided into groups of 377 high risk (score $\geq 64)$, medium risk $(27 \leq$ score $<64$ ), and low risk (score $<27$ ) and shaded 378 by overall certainty score. $\mathbf{B}$ The number of taxa associated with each of the pathways of 379 arrival. Multiple pathways could be assigned to a single taxon. $\mathbf{C}$ The relationship between 
380

381

382

383

384

385

386

387

388

389

390

391

392

393

394

395

396

397

398

399

400

401

402

403

404

405

406

407

408

409

410

411

412

413

414

415

416

417

418

419

420

421

422 certainty and the overall risk score, averaged across all taxa. Letters above bars indicate significant differences in overall risk score among certainty scores with $P<0.05$.

\section{Low risk taxa}

Seventy taxa received low risk scores (less than 27; Fig. 3). One taxon, Poa trivalis (overall risk score $=20$, overall certainty $=$ high), was considered very likely to arrive in Florida (arrival score $=5$ ) because it is in the southeastern U.S., has been used in at least one research experiment in Florida, and it is planted in golf courses in the southeast both intentionally and unintentionally (seed contaminant). Poa trivalis, however, is unlikely to establish in Florida (establishment score $=2$ ) and have impacts (impact score =2). Sambucus nigra ssp. nigra (overall risk score $=10$, overall certainty $=$ very low), was considered very likely to establish in Florida (establishment score $=5$ ) because the species Sambucus nigra occurs in multiple locations with climate similar to Florida (Table S2). However, the subspecies has few recorded occurrences globally, which led to very low certainty about the establishment score. In addition, Sambucus nigra ssp. nigra is very unlikely to arrive in Florida (arrival score =1) and unlikely to have impacts (impact score $=2$ ). None of the plant taxa in the low risk group were considered very likely to have negative impacts. We had high certainty about the scores of eight taxa, medium certainty about the scores of 43 taxa, low certainty about the scores of 16 taxa, and very low certainty about the scores of three taxa. The three taxa for which we had very low certainty about their scores were Filipendula vulgaris (overall risk score $=12$ ), $S$. nigra ssp. nigra (overall risk score $=10$ ), and Gnaphalium uliginosum (overall risk score $=$ 4).

\section{Pathways of arrival}

The most likely pathway of arrival for the taxa on the final list was escape from confinement (Fig. 3B). Taxa are also likely to arrive in Florida as transport contaminants, transport stowaways, or with unaided dispersal. It is less likely that plants will arrive through intentional release into nature or through a constructed corridor.

\section{Analysis of risk scores}

There was no significant difference in the overall risk scores before and after peer-review and consensus building $(t=-1.41,95 \% \mathrm{CI}=-4.43-1.61, \mathrm{df}=97, P=0.357)$ with an average score $( \pm \mathrm{SE})$ of $21.3 \pm 2.1$ before and $22.7 \pm 2.1$ after. The assessor $\left(\chi^{2}=27.0, \mathrm{df}=8, P<\right.$ $0.001)$, certainty level $\left(\chi^{2}=21.4, \mathrm{df}=3, P<0.001\right)$, and earliest record in the U.S. $\left(\chi^{2}=3.9\right.$, $\mathrm{df}=1, P=0.050)$ significantly affected the overall risk score, while the habitat (terrestrial vs. aquatic; $\left.\chi^{2}=0.07, \mathrm{df}=1, P=0.787\right)$ and number of records in the U.S. $\left(\chi^{2}=1.7, \mathrm{df}=1, P=\right.$ 0.196 ) did not. Four out of 36 pairwise comparisons of assessors were significantly different with $P<0.05$. Taxa with higher overall certainty scores also had higher overall risk scores (Fig. 3C). Taxa with earlier first records in the U.S. received higher overall risk scores than taxa with later first records (Fig. 4A), but taxa with more records in the U.S. did not receive significantly higher overall risk scores than taxa with fewer records, although there was a positive trend (Fig. 4B). 
423

424

425

426

427

428

429

430

431

432

433

434

435

436

437

438

439

440

441

442

443

444

445

446

447

448

449

450

451

452

453
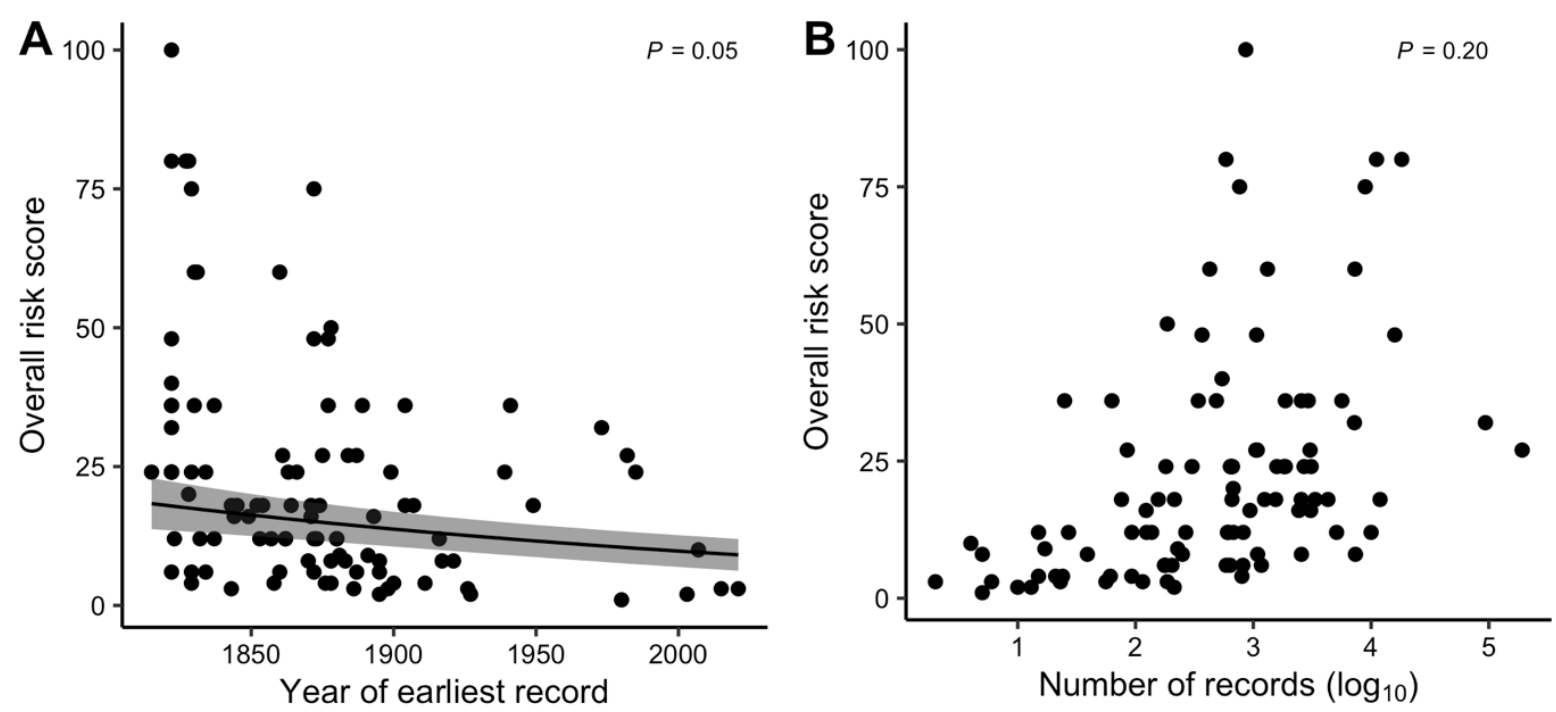

Figure 4. Earliest record and number of records. The overall risk score and $\mathbf{A}$ the year of the earliest record in the U.S. and $\mathbf{B}$ the number of records (displayed on a $\log _{10}$ scale for clarity) in the U.S. for the 99 taxa on the final list. Points represent data while lines and shading represent model-estimated mean \pm SE.

\section{Taxa characteristics}

Four families were significantly overrepresented in the final list of 99 taxa compared to the number of accepted species in the family (Suppl. material 4: Table S3): Juncacea (3 taxa out of 581 accepted species), Poaceae (21 taxa/11883 accepted species), Polygonaceae (4 taxa/1584 accepted species), and Rosaceae (7 taxa/5325 accepted species). These four families were also significantly overrepresented in the CABI list (Suppl. material 5: Table S4): 21 taxa (1\% of the CABI list) were in Juncaceae, 226 taxa (11\%) were in Poaceae, 37 taxa (2\%) were in Polygonaceae, and 80 taxa (4\%) were in Rosaceae. None of the families present on the final list were significantly underrepresented.

Ninety three percent of taxa on the final list had native ranges that included Europe and Central Asia, 75\% included the Middle East and North Africa, and 67\% included East Asia and the Pacific (Fig. 5A). Other regions were included in $43 \%$ or fewer of the taxa's native ranges. The United States was included in the native ranges of 11 taxa: Bolboschoenus maritimus, Carex nigra, Deschampsia cespitosa, Elodea nuttallii, Fragaria vesca, Geranium robertianum, Juncus articulatus, Lupinus polyphyllus, Phalaris arundinacea, Potamogeton natans, and Sanguisorba officinalis. Although some native populations of $P$. arundinacea exist in North America, the majority of populations are Eurasian genotypes (Jakubowski et al. 2014, Kettenring et al. 2019). The remaining ten taxa are native to some U.S. states, but are not in Florida (USDA 2019). Eighty nine percent of the taxa on the final list have been introduced to North America (Fig. 5B). This region was followed closely by East Asia and the Pacific (79\% of taxa), Europe and Central Asia (71\% of taxa), and Latin America and the Caribbean (69\% of taxa). Other regions were included in $40 \%$ or fewer of the taxa's introduced ranges. 
A

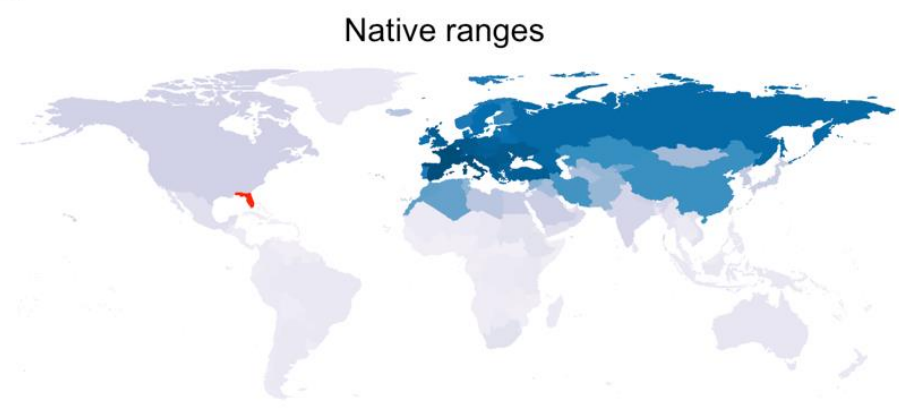

B

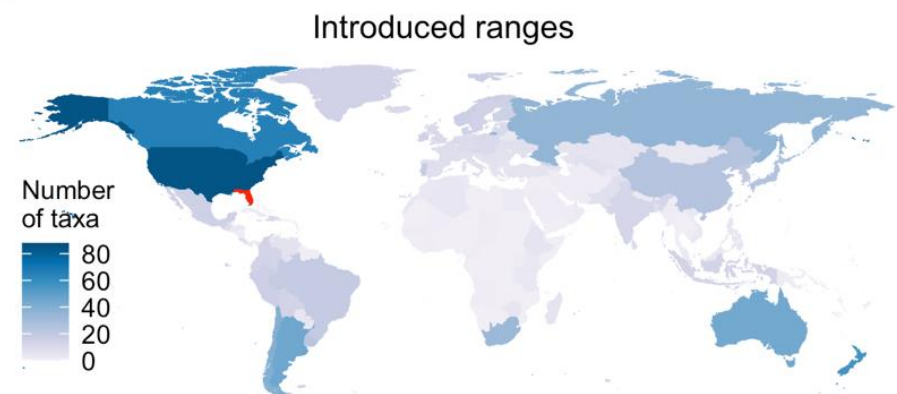

Figure 5. Ranges of taxa. A Native and $\mathbf{B}$ introduced ranges of the final list of taxa generalized at the country level. Countries with darker shades indicate a greater number of taxa native or introduced to the area. The state of Florida is in red.

\section{Discussion}

Our analysis of the 99 plant taxa most likely to be introduced to Florida identified six that have a high risk of becoming invasive in the state in the next ten years (2020-2030). The horizon scanning process helped us identify taxa that should undergo more thorough risk assessments and potentially receive policy restrictions or research priority. The process we used is a reproducible methodology that can be applied to future horizon scans.

Four taxa (Ligustrum vulgare, Cytisus scoparius, Phalaris arundinacea, and Avena fatua) had high risk scores with high certainty. We recommend that these taxa receive more thorough risk assessments followed by consideration for monitoring or regulation by the relevant state agencies. Phalaris arundinacea was assessed by the University of Florida Institute of Food and Agricultural Sciences Assessment of Non-native Plants in Florida's Natural Areas, which uses a predictive tool of 49 questions, and found to be a high invasion risk (University of Florida 2014). In our rapid risk assessments, two taxa (Agrostis capillaris and Persicaria hydropiper) had high risk scores, but assessors had medium certainty about these scores. Competition studies should be conducted with A. capillaris to increase certainty, as experts were unsure how A. capillaris would fare in competition with native Florida grasses. Experts also identified the need for agricultural impact studies of $P$. hydropiper, which interferes with crops and grazing in other regions (Suppl. material 3: Table S2). If the high level of risk assigned to the top six taxa is supported following additional research and more thorough risk assessments, we recommend regulators consider policy actions to limit the introduction of these taxa to Florida. Specifically, the industries that use or unintentionally disperse these taxa (Table 2) should limit their potential for escape. U.S. states in which the taxa are included in noxious weed lists or laws (EDDMapS 2021) could be consulted for prevention approaches. 
We identified "escape from confinement" as the most likely pathway for taxa on our final list to arrive in Florida's natural areas. This pathway includes escape from agriculture, botanical gardens, forestry, horticulture, ornamental sources other than horticulture, and research (CBD 2014). Indeed, most terrestrial plant species in a global database of invasive species and in lists of non-native species in Europe arrived by escaping confinement (Hulme et al. 2008). Domestication of species for food, ornamental purposes, and biofuel can select for traits that increase invasion risk, including fast growth rates, high fecundity, and the ability to hybridize (Petri et al. 2021). However, selection for traits that reduce invasion risk and do not interfere with the commercial purposes of plants could help prevent escape from confinement (Petri et al. 2021). For example, scientists at the University of Florida have developed sterile, low risk cultivars of the invasive species Lantana camara for landscape use within the state (Czarnecki et al. 2012).

Taxa on our final list were also likely to arrive in Florida's natural areas as transport contaminants, transport stowaways, or through unaided dispersal. Florida's seaports are some of the most active in the country (US Army Corps of Engineers 2018), hosting global and domestic imports and exports, as well as millions of cruise passengers (Florida Department of Transportation 2017). Florida is also a top tourist destination, attracting well over 100 million visitors from within and outside of the U.S. each year (VISIT FLORIDA 2020). These high movement rates provide ample opportunities for plant propagules to enter the state. The risk of introducing taxa through consistent trade routes, however, can be mitigated by identifying steps in the process of importing, processing, and storing goods that can be modified to reduce plant survival (Hulme 2009).

The identity of the assessor, the assessor's certainty level, and the invasion history of the taxa in the U.S. significantly affected the overall risk scores of the assessed taxa. Two experts, who had extensive experience completing plant risk assessments, scored taxa consistently higher than two other experts, who had less experience completing plant risk assessments. To address this issue, future horizon scans could calibrate scores among experts with a set of test taxa prior to beginning the rapid risk assessments. We hypothesize that overall risk scores are correlated with overall certainty scores because more available data on a taxon contributes to higher certainty and can provide more pieces of evidence that a taxon may arrive, establish, or have impacts. Similarly, we hypothesize that taxa with earlier and more records of occurrence in the U.S. are likely to be better represented in English-language texts than taxa that are less common or more recently detected, leading to more evidence for arrival, establishment, and impacts, which could explain their generally higher risk scores. Efforts to synthesize and standardize information about invasive species (Simpson et al. 2019, CABI 2021) could reduce these potential sources of bias.

The families Juncacea, Poaceae, Polygonaceae, and Rosaceae were significantly overrepresented in both the final horizon scan list and the initial CABI list compared to the number of accepted species in these families. These families, especially Poaceae, Polygonaceae, and Rosaceae, are similarly overrepresented in global lists of naturalized plants (Daehler 1998, Pyšek 1998, Pyšek et al. 2017). Rushes (Juncaceae) can produce large amounts of seed, expand clonally, and resist herbivory through low palatability (Ashby et al. 2020). Grasses (Poaceae) have wide ranges of environmental tolerance, are frequently transported for human uses, and can grow quickly, outcompete resident species, tolerate disturbances, and alter ecosystem processes (Pyšek 1998, Canavan et al. 2019). In addition, mis-identified invasive rushes and grasses may go undiscovered for long periods, allowing them to establish self-sustaining populations before being controlled (Scott and Hallam 2003, 
535 Pyšek et al. 2013). Knotweeds (Polygonaceae) are diverse in growth form (i.e., perennial 536 herbs, shrubs, trees, and vines) and include some aggressive invasive species (Brandbyge 1993, Gerber et al. 2008). Roses (Rosaceae) are also diverse in growth form and are frequently planted by humans as crops, ornamentals, and medicinals (Hummer and Janick 2009). Although none of the families included in the final horizon scan list were significantly underrepresented, some large families, such as Orchidaceae, were completely absent and are underrepresented in larger lists of naturalized species (Daehler 1998, Pyšek 1998, Pyšek et al. 2017). Such general trends can help identify families on which to concentrate risk assessment resources.

Most of the taxa that made our final list were native to Europe, Asia, and North Africa. Europe is the native range for a disproportionately high number of naturalized plant species relative to the number of native plant species (van Kleunen et al. 2015), which may be influenced by plant adaptations to European pastoralism and cultivation-practices that have been adopted in regions outside of Europe (MacDougall et al. 2018) — and historical exchange between Europe and other geographic regions (Pyšek et al. 2015). Temperate Asia is also a major source of global naturalized plant species (van Kleunen et al. 2015). Because Florida's Köppen-Geiger climate zones most consistently overlap with Central and South America, central Africa, and southern and eastern Asia (Kottek et al. 2006), our final list likely omits key high-risk taxa. However, propagule pressure significantly contributes to invasive species success (Lockwood et al. 2005, Cassey et al. 2018) and Europe is one of the top sources of tourists and merchandise imports for Florida (VISIT FLORIDA 2020, U.S. Department of Commerce 2021), suggesting that the taxa in the final list are of legitimate concern. Future horizon scans could focus on taxa from geographic regions with strong trade and tourism ties to the focal area, allowing for more targeted assessments.

GBIF is a powerful tool, connecting organizations and institutions that collect and store biodiversity data and making that data publicly available (GBIF.org 2020). We used GBIF data multiple times during our horizon scan: to select the top 100 taxa based on global occurrences, to evaluate arrival risk based on how close occurrences were to Florida, and to evaluate establishment risk based on whether taxa were found in areas with the same Köppen-Geiger zones as Florida. Two potential sources of bias introduced by the GBIF dataset are amateur identification of plants and records collected non-systematically across geographies. Some plant species and subspecies are difficult to differentiate from one another, leading to inaccurate records by amateur botanists (Scott and Hallam 2003). However, of the 461,876 U.S. occurrences in GBIF for taxa in our final list, only $0.06 \%$ of them were recorded by iNaturalist users (GBIF.org 2021b, iNaturalist 2021), who include amateur botanists. Non-systematic sampling likely concentrates records in populated areas. Therefore, taxa that can inhabit disturbed areas, are moved around by people, and that are visually charismatic likely have more records. These traits, however, are associated with nonnative species introductions (Hobbs and Huenneke 1992, Hulme et al. 2008, Jarić et al. 2020), so they would bias our estimates of arrival risk appropriately.

This horizon scan of invasive plant threats to Florida provides a first step in reducing the impacts of invasive species on Florida's natural systems. Like other horizon scans of invasive species, the generated list informs future research efforts and policy (e.g., Matthews et al. 2014, Roy et al. 2014, Gallardo et al. 2016, Lucy et al. 2020). Our horizon scan departs from previous invasive species horizon scans, however, in important ways. First, we began with a list of 2128 potential invasive taxa that was too large to perform rapid risk assessments in a reasonable timeline. We therefore developed data-based criteria to filter the list to 100 taxa. 
These methods could be applied to other horizon scans with similar resource constraints. Second, the rapid risk assessment tool and associated rubrics led to enough consensus among experts that our final rankings relied much more on scores than on discussion and consensus building (e.g., in contrast to Roy et al. 2014, Lucy et al. 2020). A drawback of this approach is the loss of nuanced expert opinion that falls outside of the rubrics, which is an important component of horizon scans when information on a potential invasive species is limited in peer-reviewed literature (Verbrugge et al. 2019). A major advantage, however, is that this approach can be used with non-experts, which is relevant for efforts limited by available expertise (Meyers et al. 2020).

\section{Conclusion}

Here we presented a horizon scan of 2128 plant taxa, identifying six with a high invasion risk for Florida over the next ten years and 93 with medium or low invasion risk. The horizon scan process therefore can reduce the potential number of taxa requiring thorough risk assessments by three orders of magnitude. Although the process has room for improvement, the results provide researchers, regulators, and private and public land managers with a clear list of high risk species to focus on. Given the substantial impacts and costs of invaders in Florida, the ability to differentiate and focus efforts on high probability bad actors is critical.

\section{Funding}

We would like to thank the Florida Fish and Wildlife Conservation Commission and UF/IFAS Dean for Research for funding this project.

\section{Competing interests}

The authors have declared that no competing interests exist.

\section{Acknowledgments}

We thank Dale Laughinghouse and Seokmin Kim for help with processing the list, Julie Lockwood and Helen Roy for guidance on the horizon scan process, and all other participants of the Florida Invasion Threats Horizon Scan for constructive discussions.

\section{References}

Amanatidou E, Butter M, Carabias V, Könnölä T, Leis M, Saritas O, Schaper-Rinkel P, van Rij V (2012) On concepts and methods in horizon scanning: Lessons from initiating policy dialogues on emerging issues. Science and Public Policy 39: 208-221. https://doi.org/10.1093/scipol/scs017

Arel-Bundock V, Enevoldsen N, Yetman C (2018) countrycode: An R package to convert country names and country codes. Journal of Open Source Software 3: 848. https://doi.org/10.21105/joss.00848

Ashby MA, Whyatt JD, Rogers K, Marrs RH, Stevens CJ (2020) Quantifying the recent expansion of native invasive rush species in a UK upland environment. Annals of Applied Biology 177: 243-255. https://doi.org/10.1111/aab.12602

Bacher S, Blackburn TM, Essl F, Genovesi P, Heikkilä J, Jeschke JM, Jones G, Keller R, Kenis M, Kueffer C, Martinou AF, Nentwig W, Pergl J, Pyšek P, Rabitsch W, Richardson DM, Roy HE, Saul W-C, Scalera R, Vilà M, Wilson JRU, Kumschick S (2018) Socio-economic impact classification of alien taxa (SEICAT). Methods in Ecology and Evolution 9: 159-168. https://doi.org/10.1111/2041-210X.12844

Blackburn TM, Essl F, Evans T, Hulme PE, Jeschke JM, Kühn I, Kumschick S, Marková Z, Mrugała A, Nentwig W, Pergl J, Pyšek P, Rabitsch W, Ricciardi A, Richardson DM, Sendek A, Vilà M, Wilson JRU, Winter M, Genovesi P, Bacher S (2014) A unified 
640

641

642

643

644

645

646

647

648

649

650

651

652

653

654

655

656

657

658

659

660

661

662

663

664

665

666

667

668

669

670

671

672

673

674

675

676

677

678

679

680

681

682

683

684 classification of alien species based on the magnitude of their environmental impacts. PLOS Biology 12: e1001850. https://doi.org/10.1371/journal.pbio.1001850

Boyle BL, Matasci N, Mozzherin D, Rees T, Barbosa GC, Kumar Sajja R, Enquist BJ (2015) Taxonomic Name Resolution Service. Botanical Information and Ecology Network. Available from: https://tnrs.biendata.org/ (December 11, 2019).

Brandbyge J (1993) Polygonaceae. In: Kubitzki K, Rohwer JG, Bittrich V (Eds), Flowering Plants · Dicotyledons: Magnoliid, Hamamelid and Caryophyllid Families. The Families and Genera of Vascular Plants. Springer, Berlin, Heidelberg, 531-544. https://doi.org/10.1007/978-3-662-02899-5_63

Branquart E (2009) Guidelines for environmental impact assessment and classification of non-native organisms in Belgium. Belgian Biodiversity Platform Available from: https://ias.biodiversity.be/documents/ISEIA_protocol.pdf.

Brown MJF, Dicks LV, Paxton RJ, Baldock KCR, Barron AB, Chauzat M-P, Freitas BM, Goulson D, Jepsen S, Kremen C, Li J, Neumann P, Pattemore DE, Potts SG, Schweiger O, Seymour CL, Stout JC (2016) A horizon scan of future threats and opportunities for pollinators and pollination. PeerJ 4: e2249. https://doi.org/10.7717/peerj.2249

CABI (2018) Horizon Scanning Tool. CAB International, Wallingford, UK. Available from: www.cabi.org/isc.

CABI (2021) Invasive Species Compendium. CAB International, Wallingford, UK. Available from: www.cabi.org/isc.

Canavan S, Meyerson LA, Packer JG, Pyšek P, Maurel N, Lozano V, Richardson DM, Brundu G, Canavan K, Cicatelli A, Čuda J, Dawson W, Essl F, Guarino F, Guo W-Y, van Kleunen M, Kreft H, Lambertini C, Pergl J, Skálová H, Soreng RJ, Visser V, Vorontsova MS, Weigelt P, Winter M, Wilson JRU (2019) Tall-statured grasses: a useful functional group for invasion science. Biological Invasions 21: 37-58. https://doi.org/10.1007/s10530-018-1815-z

Cassey P, Delean S, Lockwood JL, Sadowski JS, Blackburn TM (2018) Dissecting the null model for biological invasions: A meta-analysis of the propagule pressure effect. PLOS Biology 16: e2005987. https://doi.org/10.1371/journal.pbio.2005987

CBD (2014) Pathways of introduction of invasive species, their prioritization and management. Convention on Biological Diversity, Montreal, CA Available from: https://www.cbd.int/doc/meetings/sbstta/sbstta-18/official/sbstta-18-09-add1-en.pdf.

Chamberlain S, Szoecs E (2013) taxize: taxonomic search and retrieval in R [version 2; peer review: 3 approved]. F1000Research 2. Available from: http://f1000research.com/articles/2-191/v2.

Chamberlain S, Oldoni D, Barve V, Desmet P, Geffert L, Mcglinn D, Ram K, rOpenSci (https://ropensci.org/) (2021) rgbif: Interface to the Global "Biodiversity" Information Facility API. Available from: https://CRAN.R-project.org/package=rgbif (March 23, 2021).

Coffman L, Gaskalla R, Godwin W, Stuart M, Bolusky B, Hall F, Hill K, Putnam A, Shannon M, LaVigne A, McGovern T, Guglielmi J, Irby E, Lane UJ, Mizell R, Russell E, Shilling D, Smith C, Stocker R, Backman L, Sekerke J, Darling A, Hancock R, Peterson M, Watson C (2001) Pest Exclusion Advisory Committee Report. Florida Department of Agriculture and Consumer Services, Tallahassee, FL Available from: https://www.fdacs.gov/ezs3download/download/25078/515994/peac-full.pdf.

Cooke SJ, Madliger CL, Cramp RL, Beardall J, Burness G, Chown SL, Clark TD, Dantzer B, de la Barrera E, Fangue NA, Franklin CE, Fuller A, Hawkes LA, Hultine KR, Hunt KE, Love OP, MacMillan HA, Mandelman JW, Mark FC, Martin LB, Newman AEM, Nicotra AB, Robinson SA, Ropert-Coudert Y, Rummer JL, Seebacher F, 
685

686

687

688

689

690

691

692

693

694

695

696

697

698

699

700

701

702

703

704

705

706

707

708

709

710

711

712

713

714

715

716

717

718

719

720

721

722

723

724

725

726

727

728

729

730

731

732

733

734

Todgham AE (2020) Reframing conservation physiology to be more inclusive, integrative, relevant and forward-looking: reflections and a horizon scan. Conservation Physiology 8: coaa016. https://doi.org/10.1093/conphys/coaa016

Czarnecki DM, Wilson SB, Knox GW, Freyre R, Deng Z (2012) UF-T3 and UF-T4: Two sterile Lantana camara cultivars. HortScience 47: 132-137. https://doi.org/10.21273/HORTSCI.47.1.132

Daehler CC (1998) The taxonomic distribution of invasive angiosperm plants: Ecological insights and comparison to agricultural weeds. Biological Conservation 84: 167-180. https://doi.org/10.1016/S0006-3207(97)00096-7

Early R, Bradley BA, Dukes JS, Lawler JJ, Olden JD, Blumenthal DM, Gonzalez P, Grosholz ED, Ibañez I, Miller LP, Sorte CJB, Tatem AJ (2016) Global threats from invasive alien species in the twenty-first century and national response capacities. Nature Communications 7: 12485. https://doi.org/10.1038/ncomms12485

EDDMapS (2021) Early Detection \& Distribution Mapping System. The University of Georgia - Center for Invasive Species and Ecosystem Health. Available from: http://www.eddmaps.org/ (July 26, 2021).

Enterprise Florida (2021) For International Companies. Enterprise Florida. Available from: https://www.enterpriseflorida.com/for-international-companies/ (May 21, 2021).

Finnoff D, Shogren JF, Leung B, Lodge D (2007) Take a risk: Preferring prevention over control of biological invaders. Ecological Economics 62: 216-222. https://doi.org/10.1016/j.ecolecon.2006.03.025

FISC (2019) 2019 FLEPPC List of Invasive Plant Species. Florida Invasive Species Council. Available from: https://floridainvasivespecies.org/plantlist2019.cfm (March 9, 2020).

Florida Department of Transportation (2017) 2016 Florida Seaport Profiles. Seaport Office, Tallahassee, FL, USA Available from: https://www.fdot.gov/seaport/publications.shtm (April 6, 2021).

Galeopsis tetrahit L. in GBIF Secretariat (2021) GBIF Backbone Taxonomy. Checklist dataset. GBIF.org. Available from: https://doi.org/10.15468/39omei (July 12, 2021).

Gallardo B, Zieritz A, Adriaens T, Bellard C, Boets P, Britton JR, Newman JR, van Valkenburg JLCH, Aldridge DC (2016) Trans-national horizon scanning for invasive non-native species: a case study in western Europe. Biological Invasions 18: 17-30. https://doi.org/10.1007/s10530-015-0986-0

GBIF.org (2020) GBIF Home Page. Global Biodiversity Information Facility. Available from: https://www.gbif.org/.

GBIF.org (2021a) GBIF Occurrence Download. Available from: https://doi.org/10.15468/dl.v29uy7 (June 24, 2021).

GBIF.org (2021b) GBIF Occurrence Download. Available from: https://doi.org/10.15468/dl.qh62zw (August 4, 2021).

Gerber E, Krebs C, Murrell C, Moretti M, Rocklin R, Schaffner U (2008) Exotic invasive knotweeds (Fallopia spp.) negatively affect native plant and invertebrate assemblages in European riparian habitats. Biological Conservation 141: 646-654. https://doi.org/10.1016/j.biocon.2007.12.009

Gordon DR, Thomas KP (1997) Florida's Invasion by Nonindigenous Plants: History, Screening, and Regulation. In: Strangers in Paradise: Impact and Management of Nonindigenous Species in Florida. The National Academic Press, Washington, D.C., USA, 21-38.

Gusset M, Fa JE, Sutherland WJ, the Horizon Scanners for Zoos and Aquariums (2014) A horizon scan for species conservation by zoos and aquariums. Zoo Biology: 375-380. https://doi.org/10.1002/zoo.21153

Harrower CA, Scalera R, Pagad S, Schonrogge K, Roy HE (2018) Guidance for 
interpretation of the categories on introduction pathways under the convention on biological diversity. Convention on Biological Diversity Available from: https://www.cbd.int/doc/c/9d85/3bc5/d640f059d03acd717602cd76/sbstta-22-inf-09en.pdf.

Hartig F, Lohse L (2020) DHARMa: Residual Diagnostics for Hierarchical (Multi-Level / Mixed) Regression Models. Available from: https://CRAN.Rproject.org/package $=$ DHARMa $($ March 23, 2021).

Hawkins CL, Bacher S, Essl F, Hulme PE, Jeschke JM, Kühn I, Kumschick S, Nentwig W, Pergl J, Pyšek P, Rabitsch W, Richardson DM, Vilà M, Wilson JRU, Genovesi P, Blackburn TM (2015) Framework and guidelines for implementing the proposed IUCN Environmental Impact Classification for Alien Taxa (EICAT). Diversity and Distributions 21: 1360-1363. https://doi.org/10.1111/ddi.12379

Hiatt D, Serbesoff-King K, Lieurance D, Gordon DR, Flory SL (2019) Allocation of invasive plant management expenditures for conservation: Lessons from Florida, USA. Conservation Science and Practice 1: e51. https://doi.org/10.1111/csp2.51

Hobbs RJ, Huenneke LF (1992) Disturbance, diversity, and invasion: Implications for conservation. Conservation Biology 6: 324-337.

Huang P, Lamm A (2016) Identifying invasive species educational needs in Florida: Opportunities for extension. The Journal of Extension 54. Available from: https://tigerprints.clemson.edu/joe/vol54/iss5/11.

Hulme PE (2009) Trade, transport and trouble: managing invasive species pathways in an era of globalization. Journal of Applied Ecology 46: 10-18. https://doi.org/10.1111/j.1365-2664.2008.01600.x

Hulme PE, Bacher S, Kenis M, Klotz S, Kühn I, Minchin D, Nentwig W, Olenin S, Panov V, Pergl J, Pyšek P, Roques A, Sol D, Solarz W, Vilà M (2008) Grasping at the routes of biological invasions: a framework for integrating pathways into policy. Journal of Applied Ecology 45: 403-414. https://doi.org/10.1111/j.1365-2664.2007.01442.x

Hummer KE, Janick J (2009) Rosaceae: Taxonomy, Economic Importance, Genomics. In: Folta KM, Gardiner SE (Eds), Genetics and Genomics of Rosaceae. Plant Genetics and Genomics: Crops and Models. Springer, New York, NY, 1-17. https://doi.org/10.1007/978-0-387-77491-6_1

iNaturalist (2021) iNaturalist. Available from: https://www.inaturalist.org (July 16, 2021). ITIS Integrated Taxonomic Information System. Available from: https://www.itis.gov/ (December 11, 2020).

Jakubowski AR, Jackson RD, Casler MD (2014) The history of reed canarygrass in North America: Persistence of natives among invading Eurasian populations. Crop Science 54: 210-219. https://doi.org/10.2135/cropsci2013.05.0342

Jarić I, Courchamp F, Correia RA, Crowley SL, Essl F, Fischer A, González-Moreno P, Kalinkat G, Lambin X, Lenzner B (2020) The role of species charisma in biological invasions. Frontiers in Ecology and the Environment 18: 345-353.

Keller RP, Lodge DM, Finnoff DC (2007) Risk assessment for invasive species produces net bioeconomic benefits. Proceedings of the National Academy of Sciences 104: 203207. https://doi.org/10.1073/pnas.0605787104

Kettenring KM, Menuz DR, Mock KE (2019) The nativity and distribution of the cryptic invader Phalaris arundinacea (reed canarygrass) in riparian areas of the Columbia and Missouri river basins. Wetlands 39: 55-66. https://doi.org/10.1007/s13157-018-1074$\mathrm{x}$

van Kleunen M, Pyšek P, Dawson W, Essl F, Kreft H, Pergl J, Weigelt P, Stein A, Dullinger S, König C (2019) The Global Naturalized Alien Flora (GloNAF) database. Ecology 100: e02542. 
van Kleunen M, Dawson W, Essl F, Pergl J, Winter M, Weber E, Kreft H, Weigelt P, Kartesz J, Nishino M, Antonova LA, Barcelona JF, Cabezas FJ, Cárdenas D, Cárdenas-Toro J, Castaño N, Chacón E, Chatelain C, Ebel AL, Figueiredo E, Fuentes N, Groom QJ, Henderson L, Inderjit, Kupriyanov A, Masciadri S, Meerman J, Morozova O, Moser D, Nickrent DL, Patzelt A, Pelser PB, Baptiste MP, Poopath M, Schulze M, Seebens H, Shu W, Thomas J, Velayos M, Wieringa JJ, Pyšek P (2015) Global exchange and accumulation of non-native plants. Nature 525: 100-103. https://doi.org/10.1038/nature14910

Könnölä T, Salo A, Cagnin C, Carabias V, Vilkkumaa E (2012) Facing the future: Scanning, synthesizing and sense-making in horizon scanning. Science and Public Policy 39: 222-231. https://doi.org/10.1093/scipol/scs021

Kottek M, Grieser J, Beck C, Rudolf B, Rubel F (2006) World map of the Köppen-Geiger climate classification updated. Meteorologische Zeitschrift 15: 259-263.

Lenth RV, Buerkner P, Herve M, Love J, Riebl H, Singmann H (2021) emmeans: Estimated Marginal Means, aka Least-Squares Means. Available from: https://CRAN.Rproject.org/package=emmeans (March 23, 2021).

Lockwood JL, Cassey P, Blackburn T (2005) The role of propagule pressure in explaining species invasions. Trends in Ecology \& Evolution 20: 223-228. https://doi.org/10.1016/j.tree.2005.02.004

Lovell SJ, Stone SF (2005) The Economic Impacts of Aquatic Invasive Species: A Review of the Literature. U.S. Environmental Protection Agency, National Center for Environmental Economics. Working Paper Available from: https://www.epa.gov/sites/production/files/201412/documents/economic_impacts_of_aquatic_invasive_species.pdf.

Lucy F, Davis E, Anderson R, Booy O, Bradley K, Britton JR, Byrne C, Caffrey JM, Coughlan NE, Crane K, Cuthbert RN, Dick JTA, Dickey JWE, Fisher J, Gallagher C, Harrison S, Jebb M, Johnson M, Lawton C, Lyons D, Mackie T, Maggs C, Marnell F, McLoughlin T, Minchin D, Monaghan O, Montgomery I, Moore N, Morrison L, Muir R, Nelson B, Niven A, O'Flynn C, Osborne B, O'Riordan RM, Reid N, Roy H, Sheehan R, Stewart D, Sullivan M, Tierney P, Treacy P, Tricarico E, Trodd W (2020) Horizon scan of invasive alien species for the island of Ireland. Management of Biological Invasions 11: 155-177. https://doi.org/10.3391/mbi.2020.11.2.01

van der Maaden T, de Bruijn ACP, Vonk R, Weda M, Koopmanschap MA, Geertsma RE (2018) Horizon scan of medical technologies: Technologies with an expected impact on the organisation and expenditure of healthcare. National Institute for Public Health and the Environment, The Netherlands. Report https://doi.org/10.21945/RIVM-20180064

MacDougall AS, McCune JL, Eriksson O, Cousins SAO, Pärtel M, Firn J, Hierro JL (2018) The Neolithic Plant Invasion Hypothesis: the role of preadaptation and disturbance in grassland invasion. New Phytologist 220: 94-103. https://doi.org/10.1111/nph.15285

Matthews J, Beringen R, Creemers R, Hollander H, van Kessel N, van Kleef H, van de Koppel S, Lemaire AJJ, Odé B, van der Velde G, Verbrugge LNH, Leuven RSEW (2014) Horizonscanning for new invasive nonnative species in the Netherlands. Institute for Water and Wetland Research, Radboud University Nijmegen, The Netherlands Available from: https://repository.ubn.ru.nl/bitstream/handle/2066/131980/131980.pdf.

Meyers NM, Reaser JK, Hoff MH (2020) Instituting a national early detection and rapid response program: needs for building federal risk screening capacity. Biological Invasions 22: 53-65. https://doi.org/10.1007/s10530-019-02144-0

Native Plant Trust (2021) Persicaria hydropiper (water-pepper smartweed). Go Botany. 
835

836

837

838

839

840

841

842

843

844

845

846

847

848

849

850

851

852

853

854

855

856

857

858

859

860

861

862

863

864

865

866

867

868

869

870

871

872

873

874

875

876

877

878

879

880

881

882

883

884
Available from: https://gobotany.nativeplanttrust.org/species/persicaria/hydropiper/ (July 26, 2021).

Parrott D, Roy S, Baker R, Cannon R, Eyre D, Hill M, Wagner M, Preston C, Roy H, Beckman B, Copp GH, Edmonds N, Ellis J, Laing I, Britton JR, Gozlan RE, Mumford J (2009) Horizon scanning for new invasive non-native animal species in England. Natural England, England Available from: http://publications.naturalengland.org.uk/publication/43005 (May 13, 2021).

Petri T, Canavan S, Gordon DR, Lieurance D, Flory SL (2021) Potential effects of domestication on non-native plant invasion risk. Plant Ecology. https://doi.org/10.1007/s11258-021-01130-8

Pimentel D (2009) Invasive Plants: Their Role in Species Extinctions and Economic Losses to Agriculture in the USA. In: Inderjit (Ed.), Management of Invasive Weeds. Invading Nature - Springer Series In Invasion Ecology. Springer, Dordrecht, 1-7. https://doi.org/10.1007/978-1-4020-9202-2_1

PlantScout (2020) PlantScout. Dave's Garden. Available from: https://davesgarden.com/products/ps/.

POWO (2021) Plants of the World Online. Available from: http://www.plantsoftheworldonline.org/ (February 26, 2021).

Pyšek P (1998) Is there a taxonomic pattern to plant invasions? Oikos 82: 282-294. https://doi.org/10.2307/3546968

Pyšek P, Hulme PE, Meyerson LA, Smith GF, Boatwright JS, Crouch NR, Figueiredo E, Foxcroft LC, Jarošík V, Richardson DM, Suda J, Wilson JRU (2013) Hitting the right target: taxonomic challenges for, and of, plant invasions. AoB PLANTS 5. https://doi.org/10.1093/aobpla/plt042

Pyšek P, Manceur AM, Alba C, McGregor KF, Pergl J, Štajerová K, Chytrý M, Danihelka J, Kartesz J, Klimešová J, Lučanová M, Moravcová L, Nishino M, Sádlo J, Suda J, Tichý L, Kühn I (2015) Naturalization of central European plants in North America: species traits, habitats, propagule pressure, residence time. Ecology 96: 762-774. https://doi.org/10.1890/14-1005.1

Pyšek P, Pergl J, Essl F, Lenzner B, Dawson W, Kreft H, Weigelt P, Winter M, Kartesz J, Nishino M, Antonova LA, Barcelona JF, Cabesaz FJ, Cárdenas D, Cárdenas-Toro J, Castaño N, Chacón E, Chatelain C, Dullinger S, Ebel AL, Figueiredo E, Fuentes N, Genovesi P, Groom QJ, Henderson L, Inderjit, Kupriyanov A, Masciadri S, Maurel N, Meerman J, Morozova O, Moser D, Nickrent D, Nowak PM, Pagad S, Patzelt A, Pelser PB, Seebens H, Shu W, Thomas J, Velayos M, Weber E, Wieringa JJ, Baptiste MP, Kleunen M van (2017) Naturalized alien flora of the world: species diversity, taxonomic and phylogenetic patterns, geographic distribution and global hotspots of plant invasion. Preslia 89: 203-274. https://doi.org/10.23855/preslia.2017.203

R Core Team (2020) R: A language and environment for statistical computing. R Foundation for Statistical Computing, Vienna, Austria. Available from: https://www.Rproject.org/.

Randall RP (2017) A Global Compendium of Weeds. RP Randall. Available from: http://www.hear.org/gcw/scientificnames/ (February 4, 2020).

Ricciardi A, Blackburn TM, Carlton JT, Dick JTA, Hulme PE, Iacarella JC, Jeschke JM, Liebhold AM, Lockwood JL, MacIsaac HJ, Pyšek P, Richardson DM, Ruiz GM, Simberloff D, Sutherland WJ, Wardle DA, Aldridge DC (2017) Invasion science: A horizon scan of emerging challenges and opportunities. Trends in Ecology \& Evolution 32: 464-474. https://doi.org/10.1016/j.tree.2017.03.007

Rosenthal M (2020) Betrock's Plant Search. Betrock's Plant Search. Available from: plantsearch.com/new/search_plants.cfm. 
Roy HE, Peyton J, Aldridge DC, Bantock T, Blackburn TM, Britton R, Clark P, Cook E, Dehnen-Schmutz K, Dines T, Dobson M, Edwards F, Harrower C, Harvey MC, Minchin D, Noble DG, Parrott D, Pocock MJO, Preston CD, Roy S, Salisbury A, Schönrogge K, Sewell J, Shaw RH, Stebbing P, Stewart AJA, Walker KJ (2014) Horizon scanning for invasive alien species with the potential to threaten biodiversity in Great Britain. Global Change Biology 20: 3859-3871. https://doi.org/10.1111/gcb.12603

Roy HE, Adriaens T, Aldridge DC, Bacher S, Bishop JDD, Blackburn TM, Branquart E, Brodie J, Carboneras C, Cook EJ, Copp GH, Dean HJ, Eilenberg J, Essl F, Gallardo B, Garcia M, Garcia-Berthou E, Genovesi P, Hulme PE, Kenis M, Kerckhof F, Kettunen M, Minchin D, Nentwig W, Nieto A, Pergl J, Prescott O, Peyton J, Preda C, Rabitsch W, Roques A, Rorke S, Scalera R, Schindler S, Schonrogge K, Sewell J, Solarz W, Stewart A, Tricarico E, Vanderhoeven S, van der Velde G, Vila M, Wood CA, Zenetos A (2015) Invasive Alien Species - Prioritising prevention efforts through horizon scanning. European Commission, Brussels Available from: https://ec.europa.eu/environment/nature/invasivealien/docs/Prioritising\%20prevention $\% 20$ efforts $\% 20$ through\%20horizon\%20scanning.pdf.

Scott WA, Hallam CJ (2003) Assessing species misidentification rates through quality assurance of vegetation monitoring. Plant Ecology 165: 101-115. https://doi.org/10.1023/A:1021441331839

Seebens H, Bacher S, Blackburn TM, Capinha C, Dawson W, Dullinger S, Genovesi P, Hulme PE, Kleunen M van, Kühn I, Jeschke JM, Lenzner B, Liebhold AM, Pattison Z, Pergl J, Pyšek P, Winter M, Essl F (2020) Projecting the continental accumulation of alien species through to 2050. Global Change Biology n/a. https://doi.org/10.1111/gcb.15333

Seebens H, Blackburn TM, Dyer EE, Genovesi P, Hulme PE, Jeschke JM, Pagad S, Pyšek P, Winter M, Arianoutsou M, Bacher S, Blasius B, Brundu G, Capinha C, CelestiGrapow L, Dawson W, Dullinger S, Fuentes N, Jäger H, Kartesz J, Kenis M, Kreft H, Kühn I, Lenzner B, Liebhold A, Mosena A, Moser D, Nishino M, Pearman D, Pergl J, Rabitsch W, Rojas-Sandoval J, Roques A, Rorke S, Rossinelli S, Roy HE, Scalera R, Schindler S, Štajerová K, Tokarska-Guzik B, van Kleunen M, Walker K, Weigelt P, Yamanaka T, Essl F (2017) No saturation in the accumulation of alien species worldwide. Nature Communications 8: 14435. https://doi.org/10.1038/ncomms 14435

Sheley RL, Sheley JL, Smith BS (2015) Economic savings from invasive plant prevention. Weed Science 63: 296-301. https://doi.org/10.1614/WS-D-14-00004.1

Simberloff D (1997a) Nonindigenous Species-A Global Threat to Biodiversity and Stability. In: Nature and Human Society: The Quest for a Sustainable World. The National Academic PRess, Washington, DC, USA, 325-336. https://doi.org/10.17226/6142

Simberloff D (1997b) The Biology of Invasions. In: Strangers in Paradise: Impact and Management of Nonindigenous Species in Florida. Island Press, Washington, D.C., USA, 3-17.

Simberloff D (2003) Eradication - preventing invasions at the outset. Weed Science 51: 247253. https://doi.org/10.1614/0043-1745(2003)051[0247:EPIATO]2.0.CO;2

Simpson A, Morisette JT, Fuller P, Reaser J, Guala G (2019) Catalog of U.S. Federal Early Detection/Rapid Response Invasive Species Databases and Tools: Version 2.0. https://doi.org/10.5066/P9CNVBYR

State of Florida (2008) Aquatic plant importation, transportation, non-nursery cultivation, possession and collection. Florida Administrative Code \& Florida Administrative Register. Available from: https://www.flrules.org/gateway/RuleNo.asp?id=5B-64.011 
(March 9, 2020).

State of Florida (2020) Introduction or release of plant pests, noxious weeds, arthropods, and biological control agents. Florida Administrative Code \& Florida Administrative Register. Available from: https://www.flrules.org/gateway/ChapterHome.asp?Chapter=5B-57 (March 9, 2020). Sutherland WJ, Woodroof HJ (2009) The need for environmental horizon scanning. Trends in Ecology \& Evolution 24: 523-527. https://doi.org/10.1016/j.tree.2009.04.008

Sutherland WJ, Fleishman E, Mascia MB, Pretty J, Rudd MA (2011) Methods for collaboratively identifying research priorities and emerging issues in science and policy. Methods in Ecology and Evolution 2: 238-247. https://doi.org/10.1111/j.2041210X.2010.00083.X

Sutherland WJ, Atkinson PW, Broad S, Brown S, Clout M, Dias MP, Dicks LV, Doran H, Fleishman E, Garratt E, Gaston KJ, Hughes AC, Le Roux X, Lickorish FA, Maggs L, Palardy JE, Peck LS, Pettorelli N, Pretty J, Spalding MD, Tonneijck FH, Walpole M, Watson JEM, Wentworth J, Thornton A (2021) A 2021 horizon scan of emerging global biological conservation issues. Trends in Ecology \& Evolution 36: 87-97. https://doi.org/10.1016/j.tree.2020.10.014

TPL (2013) The Plant List. Available from: http://www.theplantlist.org/.

University of Florida I of F and AS (2014) Phalaris arundinacea. Assessment of Non-native Plants in Florida's Natural Areas. Available from: https://assessment.ifas.ufl.edu/assessments/phalaris-arundinacea/ (May 18, 2021).

US Army Corps of Engineers (2018) Waterborne tonnage for principal U.S. ports and all 50 states and U.S. territories; Waterborne tonnages for domestic, foreign, imports, exports and intra-state waterborne traffic. Institute for Water Resources. Downloadable data Available from: https://usace.contentdm.oclc.org/digital/collection/p16021coll2/id/1474 (April 5, 2021).

U.S. Congress (2000) 7 U.S.C. 7701 Plant Protection Act. Available from: https://www.aphis.usda.gov/plant_health/downloads/plant-protect-act.pdf (August 2, 2021).

U.S. Department of Commerce (2021) Florida Trade \& Economy Factsheet. International Trade Administration Available from: https://www.trade.gov/data-visualization/stateeconomy-and-trade-factsheets (May 21, 2021).

USDA (2012) USDA Plant Hardiness Zone Map. United States Department of Agriculture Agricultural Research Service. Available from: https://planthardiness.ars.usda.gov/PHZMWeb/Default.aspx (May 21, 2021).

USDA (2017) Noxious Weeds Program Home Page. Animal and Plant Health Inspection Service, U.S. Department of Agriculture. Available from: https://www.aphis.usda.gov/aphis/ourfocus/planthealth/plant-pest-and-diseaseprograms/pests-and-diseases/SA_Weeds/SA_Noxious_Weeds_Program (March 16, 2020).

USDA N (2019) The PLANTS Database. National Plant Data Team, Greensboro, NC USA. Available from: http://plants.sc.egov.usda.gov.

Venables WN, Ripley BD (2002) Modern Applied Statistics with S. Springer New York, New York, NY. https://doi.org/10.1007/978-0-387-21706-2

Verbrugge LNH, de Hoop L, Aukema R, Beringen R, Creemers RCM, van Duinen GA, Hollander H, de Hullu E, Scherpenisse M, Spikmans F, van Turnhout CAM, Wijnhoven S, Leuven RSEW (2019) Lessons learned from rapid environmental risk assessments for prioritization of alien species using expert panels. Journal of 
984

985

986

987

988

989

990

991

992

993

994

995

996

997

998

999

1000

1001

1002

1003

1004

1005

1006

1007

1008

1009

1010

1011

1012

1013

1014

1015

1016

1017

1018

1019

1020

1021

1022

1023

1024

1025

1026

1027

1028

1029

1030

1031

1032

1033

Environmental Management 249: 109405. https://doi.org/10.1016/j.jenvman.2019.109405

VISIT FLORIDA (2020) Florida Visitor Estimates. VISIT FLORIDA Research. Available from: https://www.visitflorida.org/resources/research/ (February 25, 2021).

Wunderlin RP, Hansen BF, Franck AR, Essig FB (2019) Atlas of Florida Plants. Institute for Systematic Botany, University of South Florida, Tampa, FL. Available from: https://florida.plantatlas.usf.edu/ (December 11, 2019).

\section{Figure legends}

Figure 1. Criteria for selecting taxa for rapid risk assessment. The criteria included the following systematic steps: (1) a preliminary list of 2128 taxa; (2) correcting for synonyms, which increased the original list to 2360; (3) climate matching with Köppen-Geiger climate zones (Kottek et al. 2006, CABI 2018), which identified 1504 taxa that could potentially become established in Florida if climate were the only limiting variable; (4) 197 taxa were already naturalized in Florida (Wunderlin et al. 2019) and removed from the list; (5) 57 taxa were already listed on state or federal noxious weed lists (State of Florida 2008, 2020, USDA 2017, FISC 2019) and were removed from the list; (6) taxa that were naturalized somewhere outside of their native range (van Kleunen et al. 2019), suggesting the ability to establish in habitats where they did not co-evolve with other species, were selected (912 taxa); (7) taxa with a record of "weediness", suggesting the ability to produce a self-sustaining population and have at least mild impacts on the surrounding environment (Randall 2017), were selected (808 taxa); (8) the top 100 taxa, ranked by number of global occurrences (GBIF.org 2021a), were selected. More details on the datasets used to inform these criteria can be found in Suppl. material 1: Methods S1.

Figure 2. The six taxa that were designated as high risk for invasion potential in Florida. Overall risk scores are in white circles (maximum possible score is 125). (Photos: Meneerke bloem, Isidre blanc, Andreas Eichler, Stefan.lefnaer, CC BY-SA 4.0; Robert Flogaus-Faust, CC BY 4.0; Rasbak, CC BY-SA 3.0; Willow, CC-BY 2.5; Mary Joyce, Katrice Baur, scottq1, rae117, CC BY-NC 4.0; Christian Grenier, CC0 1.0).

Figure 3. Horizon scan scores. A The overall risk scores for 99 taxa, divided into groups of high risk (score $\geq 64)$, medium risk $(27 \leq$ score $<64)$, and low risk (score $<27$ ) and shaded by overall certainty score. $\mathbf{B}$ The number of taxa associated with each of the pathways of arrival. Multiple pathways could be assigned to a single taxon. $\mathbf{C}$ The relationship between certainty and the overall risk score, averaged across all taxa. Letters above bars indicate significant differences in overall risk score among certainty scores with $P<0.05$.

Figure 4. Earliest record and number of records. The overall risk score and $\mathbf{A}$ the year of the earliest record in the U.S. and $\mathbf{B}$ the number of records (displayed on a $\log _{10}$ scale for clarity) in the U.S. for the 99 taxa on the final list. Points represent data while lines and shading represent model-estimated mean $\pm \mathrm{SE}$.

Figure 5. Ranges of taxa. A Native and $\mathbf{B}$ introduced ranges of the final list of taxa generalized at the country level. Countries with darker shades indicate a greater number of taxa native or introduced to the area. The state of Florida is in red.

\section{Supplementary materials}

Suppl. material 1. Methods for trimming the list of potential invasive species based on several criteria. 
1035 Suppl. material 2: Table S1. Potential invasive plant species provided by the CABI Horizon

1036

1037

1038 Suppl. material 3: Table S2. Reviewed rapid risk assessments of the 99 plant species in the 1039 final list, ordered by overall score.

1040

1041 Suppl. material 4: Table S3. Test of under- or overrepresentation of plant families in the 1042 final horizon scan list based on resampling of accepted species from The Plant List database.

1044 Suppl. material 5: Table S4. Test of under- or overrepresentation of plant families in the 1045 initial CABI list based on resampling of accepted species from The Plant List database.

1046

1047

1048

1049

\section{Data Availability}

Raw data and code are available at https://github.com/aekendig/fl-plants-horizon-scan. This repository will be assigned a DOI and archived with Zenodo following acceptance of the manuscript. 